\title{
Morphological and molecular diversity within Algerian cowpea (Vigna unguiculata (L.) Walp.) landraces
}

\author{
Naima Ghalmi · Marie Malice . \\ Jean-Marie Jacquemin · Sidi-Mohamed Ounane • \\ Leila Mekliche $\cdot$ Jean-Pierre Baudoin
}

Received: 2 March 2009/Accepted: 19 August 2009/Published online: 11 September 2009

(C) Springer Science+Business Media B.V. 2009

\begin{abstract}
Twenty landraces of cowpea (Vigna unguiculata (L.) Walp.) scattered throughout Algeria were compared through morphological and genetic characterization. At the morphological level, for qualitative characters there was no intra-landrace variation and for quantitative characters the variations were low except for landrace NAG2 Three different cultigroups were located in Algeria: Biflora that was dominant in the Sahara, Melanophtalmus in the North and Unguiculata including one landrace in Kabylia and two in Sahara. The AMOVA analysis indicated that the genetic variation was lower within than among agro-ecological regions. A Mantel test, revealed a correlation between the qualitative morphological data and the geographical data $(R=0.28$; $P<0.01$ ), indicating that the degree of morphological change among landraces was roughly proportional to the geographical distances separating them.
\end{abstract}

N. Ghalmi $(\bowtie) \cdot$ S.-M. Ounane · L. Mekliche Department of Crop Husbandry, National Agronomic Institute, Rue Hassen Badi, El Harrach, Algiers, Algeria e-mail: n.ghalmi@ina.dz; nawelg2000@yahoo.fr

M. Malice · J.-P. Baudoin

Tropical Crop Husbandry and Horticulture, Gembloux Agricultural University, Passage des Déportés 2, 5030 Gembloux, Belgium

J.-M. Jacquemin

Department of Biotechnology, Laboratory of Molecular Biology, Walloon Agricultural Research Centre, 234

Chaussée de Charleroi, 5030 Gembloux, Belgium
Genetic diversity was analyzed by using 11 random amplified polymorphic DNA (RAPD) and 12 intersimple sequence repeat (ISSR) markers. No intralandrace variability was found. The eleven RAPD primers yielded 77 bands, of which 45 (58.44\%) were polymorphic; the genetic similarity ranged from 66.0 to $96.7 \%$. The twelve ISSR primers provided a total of 104 bands, of which $65(62.5 \%)$ were polymorphic; the genetic similarity ranged from 62.8 to $97.8 \%$. cluster analysis showed a good match between genetic background and geographical distribution, which was confirmed by the results of the Mantel test. In particular, geographical data and genetic data were found to be correlated: $(R=0.33$; $P<0.01)$ for RAPD, $(R=0.37 ; P<0.01)$ for ISSR, and $(R=0.33 ; P<0.01)$ for a combined RAPDISSR dataset. Moreover, despite the absence of significant correlation between morphological and RAPD data $(R=0.14 ; P=0.14)$, significant correlations between morphological data and both ISSR $(R=0.27, P<0.05)$ and a combined RAPD-ISSR dataset $(R=0.22, \quad P<0.05)$ were noted. ISSR markers were better linked to morphological variation than were RAPD markers. However, despite this, genetic distances among these landraces were found to be essentially the same no matter which markers were used.

Keywords Comparative analysis . Genetic variability · ISSR · Morphological markers · RAPD · Vigna unguiculata 


\section{Introduction}

Cowpea, Vigna unguiculata (L.) Walpers $(2 n=$ $2 x=22$ ), is an important food legume in developing countries of the tropics and subtropics, especially in sub-Saharan Africa, Asia, and Central and South America (Singh et al. 1997), and in some temperate areas, including the Mediterranean region and the southern states of the USA (Pasquet 2000). A widely used classification system subdivides all domesticated forms into four cultivar groups based primarily on seed and pod characteristics (Westphal 1974; Ng and Marechal 1985). These four cultivar groups are (1) Unguiculata, grown as a pulse, (2) Biflora (catjang), mainly used as a forage, (3) Sesquipedalis (yardlong or asparagus bean), grown as a vegetable, and (4) Textilis, cultivated for the fibres of its long floral peduncles. More recently, Pasquet (1998) proposed the addition of another cultivar group, named Melanophthalmus (black-eyed pea).

Cowpea seeds possess high nutritive value (Ehlers and Hall 1997). The plants are well adapted to grow under high temperature and drought (Hall and Patel 1985) and tolerate low soil fertility due to their high rate of nitrogen fixation (Eloward and Hall 1987) and ability to form effective symbiotic mycorrhizae (Kwapata and Hall 1985). Therefore, cowpea can play an important role in agricultural development, particularly in the Algerian Sahara where the drought and salinity frequently limit crop production.

In the 1930s, several forms of Saharian cowpea cultivated in Algeria were described in two studies (Chevalier 1932; Trabut 1935). A more recent biosystematic study (Anoun and Echikh 1990) identified the various landraces of cowpea cultivated in Algeria (Kabylia, El Goléa, Adrar), mainly from two regions: Kabylia (Tiziouzou) and Saharian oases (El Goléa, Adrar). They identified two different cultivar groups of cowpea: Melanophtalmus in Kabylia and Biflora in the Sahara (Anoun and Echikh 1990). A follow-up study by Echikh (2000) evaluated the diversity of seven Saharan cultivated forms originated from El Golea, Adrar, Timimoun and Djanet and five forms cultivated in Kabylia (Tizi-ouzou) based on isoenzyme polymorphisms, Echikh (2000) identified a low genetic diversity between these traditional landraces. Nevertheless, only limited number of landraces were examinated.
In Algeria, cowpea is used in the traditional cuisine of Kabylia and the Sahara; in both places it is considered to have therapeutic properties and is mainly consumed for home consumption and subsistence. However, it is considered as a minor crop; its cultivation is based on landraces, limited to relatively few hectares. This species seems related to Berber traditional culture, and the traditional farmers of these areas, whether by choice or by need, conserve and develop local phytogenetic resources by preserving landraces and associated local knowledge.

Ex situ conservation of potentially useful populations requires a clear understanding of the genetic variation and distinctiveness of these populations. Careful characterization of accessions is a necessary first step to guide efforts to conserve biodiversity and facilitate breeding.

So far, most characterization of Algerian phytogenetic resources has been based on morphological characteristics. Such efforts often face problems with low penetrance and/or heritability, especially of quantitative traits subjected to environmental influences, and with selective pressures applied during domestication and improvement (Leakey 1988). On the other hand, molecular markers are highly heritable, available in large numbers, and often polymorphic enough to enable discrimination of closely related genotypes. In recent years, various classes of molecular markers, including random amplified polymorphic DNA (RAPD) (Nkongolo 2003; Ba et al. 2004; Badiane et al. 2004; Sarutayophat et al. 2007; Dikshit et al. 2007), AFLP (Menendez et al. 1997; Ouédraogo et al. 2002), SSR (Gillaspie et al. 2005; Li et al. 2001; Diouf and Hilu 2005) and inter-simple sequence repeat (ISSR) (Ajibade et al. 2000), have been used to detect genetic diversity in cowpea.

Random amplified polymorphic DNA is a commonly used technique since it is simple, fast, and inexpensive, and requires only small quantities of tissue for DNA extraction (Welsh and Mc Clelland 1990). However, RAPDs have been criticised because of their dominance and banding patterns are not always reliable or reproducible (Jones et al. 1997).

Inter-simple sequence repeat markers are considered more discriminating than are RAPD markers (Qian et al. 2001). They have been used to characterize genebank accessions (Blair et al. 1999; Charters and Wilkinson 2000) as well as to identify 
closely related cultivars (Fang and Roose 1997). Like for RAPD, the ISSR technique is limited because bands are scored as dominant markers, and genetic diversity estimates are based on diallelic $(1=$ band present, $0=$ band absent) characteristics (Xue-Jun et al. 2005). In Algeria, no study using molecular techniques was performed to investigate the genetic diversity of cowpea landraces.

Therefore, the objective of the present study was to determine the genetic variability and relationships among twenty landraces of cowpea from different agro-ecological zones of Algeria, based on morphological and genetic (RAPD and ISSR) markers. In addition, these molecular marker techniques are compared to each other and to morphological traits to understand the degree of congruency.

\section{Materials and methods}

Plant materials

Cowpea seeds were collected from several areas across Algeria (Table 1; Fig. 1) during years 2003, 2004, and 2005. The seeds were conserved ex situ (seeds dried and stored at $-20^{\circ} \mathrm{C}$ and multiplied in a field collection) at the "Institut Technique des Cultures Maraichères" (ITCM Staouali, Algiers). Twenty distinct collections of cowpea landraces were analyzed, and each landrace was self-pollinated twice before analysis. Among these 20 landraces, 18 were morphologically characterized (2 landraces did not flower), 19 were used for ISSR typing and all the 20 landraces were screened with RAPD markers.

The collection sites were geographically and climatically divided into three regions following the data of the ONM (National Office of Meteorology) (Table 1): (1) the region of Kabylia (Bejaia, Tiziouzou), (2) the region of El Kala, (3) the oases of Sahara (Adrar, Timimoun, Bechar, El Golea, Djanet).

Kabylia is a region in the North of Algeria, part of the Tell Atlas located at the edge of the Mediterranean Sea. Its climate is sub-humid with a temperate winter and rainfall $>700 \mathrm{~mm} /$ year. Local soils, which are composed of clay-sand to marl, are often degraded on the slopes. Family gardens are the predominant form of agricultural production. The most common species are olive, fig and almond trees. Other vegetable species are cultivated in small gardens.
Table 1 Geographic location of Algerian landraces of $V$. unguiculata

\begin{tabular}{|c|c|c|c|c|c|}
\hline \multirow{2}{*}{$\begin{array}{l}\text { Table } 1 \text { Geographic } \\
\text { location of Algerian } \\
\text { landraces of } V \text {. unguiculata }\end{array}$} & Accession & Geographical origin & Longit. & Lat. & Alt. (m) \\
\hline & NE5 & Tonga West, El Kala & $08^{\circ} 31 \mathrm{E}$ & $36^{\circ} 53 \mathrm{~N}$ & 2.2 \\
\hline & NE8 & North-East Oubaira, El Kala & $08^{\circ} 42 \mathrm{E}$ & $36^{\circ} 83 \mathrm{~N}$ & 28 \\
\hline & NE10 & Oum el Taboul,El Kala & $08^{\circ} 57 \mathrm{E}$ & $36^{\circ} 88 \mathrm{~N}$ & 9 \\
\hline & NE4 & Mellah West, El Kala & $08^{\circ} 33 \mathrm{E}$ & $36^{\circ} 87 \mathrm{~N}$ & 3 \\
\hline & NKT3 & Tiziouzou, Kabylie & $03^{\circ} 95 \mathrm{E}$ & $36^{\circ} 54 \mathrm{~N}$ & 344 \\
\hline & NKT4 & Tiziouzou, Kabylie & $03^{\circ} 95 \mathrm{E}$ & $36^{\circ} 54 \mathrm{~N}$ & 344 \\
\hline & NKT5 & Tiziouzou, Kabylie & $03^{\circ} 95 \mathrm{E}$ & $36^{\circ} 54 \mathrm{~N}$ & 344 \\
\hline & NKB7 & Bejaia, Kabylie & $04^{\circ} 85 \mathrm{E}$ & $36^{\circ} 73 \mathrm{~N}$ & 1,130 \\
\hline & NAG4 & Tsabit, Adrar & $00^{\circ} 22 \mathrm{~W}$ & $28^{\circ} 36 \mathrm{~N}$ & 249 \\
\hline & NAG5 & Tsabit, Adrar & $00^{\circ} 25 \mathrm{~W}$ & $28^{\circ} 36 \mathrm{~N}$ & 256 \\
\hline & NAT2 & Bouda, Adrar & $00^{\circ} 11 \mathrm{~W}$ & $27^{\circ} 49 \mathrm{~N}$ & 279 \\
\hline & NAT9 & Adrar & $00^{\circ} 11 \mathrm{~W}$ & $27^{\circ} 49 \mathrm{~N}$ & 279 \\
\hline & NAG6 & Oujelaine, Adrar & $00^{\circ} 22 \mathrm{~W}$ & $28^{\circ} 36 \mathrm{~N}$ & 249 \\
\hline & NG7 & El Goléa, Ghardaia & $02^{\circ} 52 \mathrm{E}$ & $30^{\circ} 34 \mathrm{~N}$ & 397 \\
\hline & NAG2 & Timimoun, Adrar & $00^{\circ} 27 \mathrm{E}$ & $29^{\circ} 30 \mathrm{~N}$ & 335 \\
\hline & $\mathrm{NB} 12$ & El Ouata, Bechar & $01^{\circ} 83 \mathrm{~W}$ & $29^{\circ} 86 \mathrm{~N}$ & 419 \\
\hline & NB18 & Timoudi, Bechar & $01^{\circ} 13 \mathrm{~W}$ & $29^{\circ} 32 \mathrm{~N}$ & 366 \\
\hline & ND3 & Azzelouaz, Djanet & $09^{\circ} 48 \mathrm{E}$ & $24^{\circ} 56 \mathrm{~N}$ & 1,148 \\
\hline & ND4 & Azzelouaz, Djanet & $09^{\circ} 48 \mathrm{E}$ & $24^{\circ} 57 \mathrm{~N}$ & 1,149 \\
\hline $\begin{array}{l}\text { Longit longitude, Lat } \\
\text { latitude, Alt altitude }\end{array}$ & ND6 & El Mihan, Djanet & $09^{\circ} 48 \mathrm{E}$ & $24^{\circ} 58 \mathrm{~N}$ & 1,117 \\
\hline
\end{tabular}

Longit longitude, Lat latitude, Alt altitude 
Fig. 1 Map of Algeria showing locations of the landrace cowpea collections

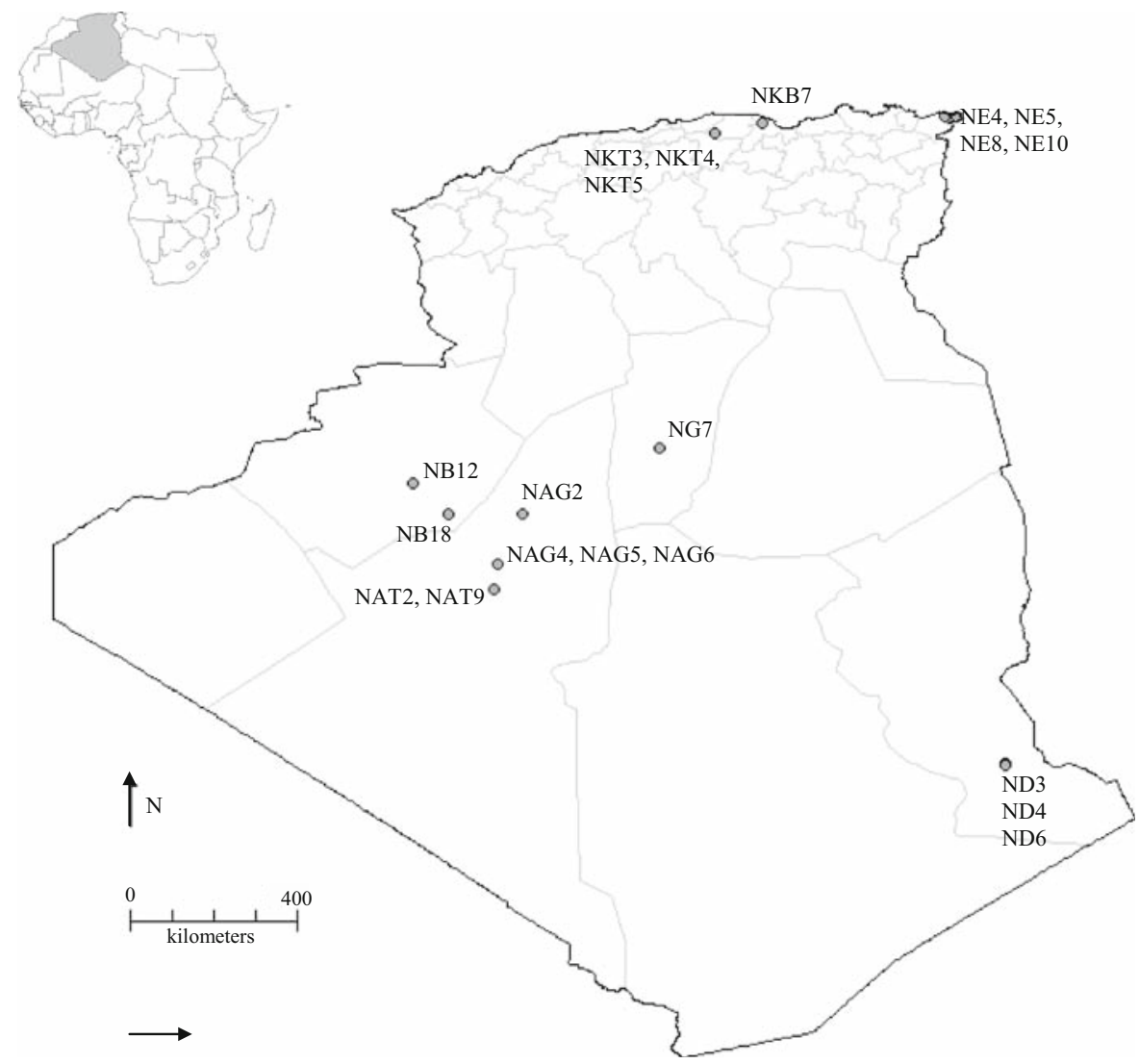

El Kala is located in the extreme Northeast of Algeria in a triangle of coastal plains and hills bounded by the Mediterranean Sea and the Tunisian border. This region contains a national natural park which is a reservoir of both plant and animal biodiversity. It was recognized as a biosphere reserve by the UNESCO. The climate of El Kala is humid to sub-humid with mild winters with annual average precipitation of 910-1,300 $\mathrm{mm}$. Several soil types are present: marshes, boggy soil, dunes, and wet meadows that become dry in the summer. Agriculture is dominated by peanut and vegetable crops.

The oases of the Sahara are characterized by a hyper-arid climate with cold winters and very hot, dry summers. Seasonal variation may be huge, from over $50^{\circ} \mathrm{C}$ during summer days, to temperatures below freezing during winter nights. Daily variation is also very important. Not only does the Sahara receive very little rain, but precipitation events are also extremely irregular, ranging from 1 to $180 \mathrm{~mm} /$ year with a high degree of evapotranspiration. Local soils are mainly comprised of sand. Oasis culture is based on multistory cropping systems with palms, fruit trees, vegetables, and cereals. In the South, the plateau of Djanet rises up from the desert, receives more rainfall and presents slightly cooler summer temperatures. These highlands support dry woodlands and shrublands distinct from the hot, dry desert lowlands. In general, soils of this region include sands and sandyalluvial soils with low salinity. The Djanet oasis is relatively rich in water supporting garden culture, palm groves, vegetables and fruit trees.

\section{Morphological characterization}

The study was carried out during the summer 2005 at the experimental fields of the ITCM, located in the northern region of Algeria, close to Algiers, at an elevation of $32 \mathrm{~m}, 02^{\circ} 53^{\prime} 08^{\prime \prime} \mathrm{E}$ longitude and $36^{\circ} 45^{\prime} 24^{\prime \prime} \mathrm{N}$ latitude. This zone is characterized by a sub-humid climate with a mild winter and a hot, dry summer. Annual precipitation ranged from 600 to $700 \mathrm{~mm}$. Half of the precipitation occurs during winter with a maximum in December. The soil type is sandy loam. 
Table 2 The 12 selected morphological descriptors used in Cowpea analysis

Descriptors

Seed colour: 1 cream, 2 cream brown, 3 brown, 4 brown ochre, 5 brown olive, 6 holstein white and black, 7 black

Eye colour: 0 absent, 1 brown, 2 brown large, 3 black

Shape: 1 kidney, 2 ovoid, 3 crowder, 4 globose, 5 rhomboid

Texture: 1 smooth, 2 smooth to rough, 3 Rough

Flower colour: 1 white, 2 pink, 3 purple-pink, 4 purple

Weight of hundred seeds (mg): weight of 100 seeds with moisture content of $12 \%$

Seed number per pod: measured on the 10 mature pods from 5 randomly selected plants

Seed length $(\mathrm{cm})$ : measured on the 10 mature seeds from 5 randomly selected plants

Pod purple pigmentation: 0 absence, 1 presence

Pod length $(\mathrm{cm})$ : measured on the 10 mature pods from 5 randomly selected plants

Number of ovules per pod: measured on the 10 mature pods from 5 randomly selected plants

Duration (days): from sowing to $50 \%$ of flowering

Source: Adapted from IBPGR (1983)

Twenty landraces were evaluated for their morphological and agronomic traits, and samples were collected from three replications of 5 plants or 15 plants per landrace. Characteristics analyzed for each sample (Table 2) included qualitative characters (purple pod pigmentation, flower colour, seed shape, eye colour, seed colour, and seed texture) and quantitative plant and seed traits (duration from sowing to 50\% flowering, pod length, number of seeds per pod, number of ovules per pod, seed length and 100-seeds weight) chosen from cowpea descriptors of the International Board for Plant Genetic Resources (IBPGR 1983).

Molecular characterization

\section{DNA extraction}

Seedlings for DNA extraction were raised in pots in a glasshouse. Leaf samples were pooled from ten 20day-old individuals of each landrace used in the morphological study. From each plant, $100 \mathrm{mg}$ of young leaf tissue was taken and frozen in liquid nitrogen for DNA extraction by using DNeasy ${ }^{\mathrm{TM}}$ Plant Mini extraction kit (Qiagen, Germany). Each sample's DNA concentration was quantified on $0.8 \%$ agarose gel and then diluted to approximately
$20 \mathrm{ng} / \mu \mathrm{l}$ for RAPD and ISSR analysis. All diluted DNA samples were stored at $-20^{\circ} \mathrm{C}$ until use.

\section{RAPD analysis}

Twenty primers (Operon Technologies Inc., Alameda, California, USA) were tested for PCR amplification. Primers were selected from those chosen for previous studies of cowpea genetic diversity (Menendez et al. 1997; Ba et al. 2004). After preliminary testing on a few samples, eleven primers that gave clear polymorphic and reproducible banding patterns were selected to assess the genetic variability of the landraces (Table 3).

Table 3 Primers used for RAPD and ISSR studies among cowpea landraces from different agro-ecological areas in Algeria

\begin{tabular}{|c|c|c|c|}
\hline & $\begin{array}{l}\text { Sequence } \\
\left(5^{\prime} \rightarrow 3^{\prime}\right)\end{array}$ & $\begin{array}{l}\text { Number } \\
\text { of bands }\end{array}$ & $\begin{array}{l}\text { Number } \\
\text { of polymorphic } \\
\text { bands }\end{array}$ \\
\hline \multicolumn{4}{|l|}{ RAPD } \\
\hline OPA13 & CAGCACCCAC & 14 & 4 \\
\hline OPA01 & CAGGCCCTTC & 7 & 4 \\
\hline OPA04 & AATCGGGCTG & 6 & 2 \\
\hline OPE18 & GGACTGCAGA & 7 & 6 \\
\hline OPE19 & ACGGCGTATG & 5 & 4 \\
\hline OPB11 & GTAGACCCGT & 8 & 7 \\
\hline OPB05 & TGCGCCCTTC & 8 & 2 \\
\hline OPB12 & CCTTGACGCA & 7 & 6 \\
\hline OPA14 & TCTGTGCTGG & 5 & 3 \\
\hline OPA02 & TGCCGAGCTG & 6 & 4 \\
\hline OPP02 & TCGGCACGCA & 4 & 3 \\
\hline Total & & 77 & 45 \\
\hline \multicolumn{4}{|l|}{ ISSR } \\
\hline A808 & $(\mathrm{AG})_{8} \mathrm{C}$ & 11 & 8 \\
\hline A811 & $(\mathrm{G} \mathrm{A})_{8} \mathrm{C}$ & 8 & 7 \\
\hline A812 & $(\mathrm{GA})_{8} \mathrm{~A}$ & 9 & 8 \\
\hline A834 & $(\mathrm{AG})_{8} \mathrm{YT}$ & 10 & 7 \\
\hline A836 & $(\mathrm{AG})_{8} \mathrm{YA}$ & 6 & 3 \\
\hline A841 & $(\mathrm{GA})_{8} \mathrm{YC}$ & 10 & 5 \\
\hline A846 & $(\mathrm{CA})_{8} \mathrm{RT}$ & 5 & 3 \\
\hline A856 & $(\mathrm{AC})_{8} \mathrm{YA}$ & 10 & 6 \\
\hline A857 & $(\mathrm{AC})_{8} \mathrm{YC}$ & 8 & 7 \\
\hline A884 & $\mathrm{HBH}(\mathrm{AG})_{7}$ & 9 & 4 \\
\hline A855 & $(\mathrm{AC})_{8} \mathrm{YT}$ & 8 & 2 \\
\hline A2 & VHV $(\mathrm{GT})_{8}$ & 10 & 5 \\
\hline Total & & 104 & 65 \\
\hline
\end{tabular}

$R$ purine, $Y$ pyrimidine, $B$ non-A, $D$ non-C, $H$ non-G 
Amplifications were carried out in $25 \mu \mathrm{l}$ volumes containing $1 \mathrm{X}$ buffer $(20 \mathrm{mM}$ Tris- $\mathrm{HCl}, 10 \mathrm{mM} \mathrm{KCl}$, $10 \mathrm{mM}\left(\mathrm{NH}_{4}\right)_{2} \mathrm{SO}_{4}, 2 \mathrm{mM} \mathrm{MgSO} 4$ and $0.1 \%$ Triton $\mathrm{X}-100\left(\mathrm{pH} 8.8\right.$ at $\left.25^{\circ} \mathrm{C}\right)$ ), $1 \mathrm{mM} \mathrm{MgCl}_{2}, 200 \mu \mathrm{M}$ dNTPs, 1.7 U Taq DNA polymerase (New England Bio Labs, Ipswich, MA, USA), $400 \mathrm{nM}$ primer and 80 ng template DNA. PCR reactions were performed in a thermal cycler (PTC 200, MJ Research Inc., San Francisco, CA, USA) programmed for an initial denaturation step $\left(2 \mathrm{~min}\right.$ at $\left.94^{\circ} \mathrm{C}\right)$, followed by 40 amplification cycles $\left(1 \mathrm{~min}\right.$ at $94^{\circ} \mathrm{C}, 1 \mathrm{~min}$ at $35^{\circ} \mathrm{C}$ and $2 \mathrm{~min}$ at $72^{\circ} \mathrm{C}$ ), one $5 \mathrm{~min}$ cycle at $72^{\circ} \mathrm{C}$, and one 30-min cycle at $30^{\circ} \mathrm{C}$ (Ba et al. 2004). Amplification products were separated by electrophoresis in $1.8 \%$ agarose gels in $0.5 \mathrm{X}$ TAE buffer, stained with ethidium bromide and photographed under UV light. Molecular weights were estimated with a 100 bp DNA Ladder Plus (GeneRuler ${ }^{\mathrm{TM}}$, Fermentas, St Leon-Rot, Germany). Each amplification was repeated at least twice to identify repeatable polymorphisms. RAPD patterns were scored as the presence or absence of clearly reproducible bands in duplicate PCR reactions. RAPD were identified by the primer used and the size, in base pairs, of the amplified product.

\section{ISSR analysis}

Twenty ISSR primers were chosen based on their performances to distinguish taxa within the genus Vigna (Ajibade et al. 2000; Souframanien and Gopalakrishna 2004). Out of the 20 chosen primers, 12 were selected for further analysis based on clarity, scorability, and reproducibility of banding patterns (Table 3).

PCR was carried out in $25 \mu 1$ volumes containing $40 \mathrm{ng}$ template DNA, $0.5 \mathrm{U}$ Taq DNA polymerase (New England BioLabs, Ipswich, MA, USA), $400 \mu \mathrm{M}$ dNTPs, $0.2 \mu \mathrm{M}$ primer and $1 \mathrm{X}$ reaction buffer that contained $20 \mathrm{mM}$ Tris- $\mathrm{HCl}, 10 \mathrm{mM} \mathrm{KCl}$, $10 \mathrm{mM}\left(\mathrm{NH}_{4}\right)_{2} \mathrm{SO}_{4}, 2 \mathrm{mM} \mathrm{MgSO} 4$ and $0.1 \%$ Triton $\mathrm{X}-100$ (pH 8.8 at $25^{\circ} \mathrm{C}$ ). Annealing temperatures were optimized for each primer by using a gradient temperature thermocycler (PTC-200, MJ research, Waltham, MA, USA), and the annealing temperature of $50^{\circ} \mathrm{C}$ was selected for all the tested primers based on preliminary profiles on agarose gel. PCR cycling conditions were: a 5-min initial denaturation step $\left(94^{\circ} \mathrm{C}\right)$; followed by 35 amplification cycles $(30 \mathrm{~s}$ at $94^{\circ} \mathrm{C}, 1 \mathrm{~min}$ at $50^{\circ} \mathrm{C}$, and $1 \mathrm{~min}$ at $72^{\circ} \mathrm{C}$ ); and a final extension step of $8 \mathrm{~min}$ at $72^{\circ} \mathrm{C}$. Amplification products were separated by agarose gel electrophoresis $(1.8 \%$ agarose in $1 \mathrm{X}$ TBE buffer) and ethidium bromide staining. After gel image capture, band sizes were determined by using a 2-Log DNA Ladder (New England BioLabs, Ipswich, MA, USA). All amplifications were repeated at least twice and only reproducible bands were considered for analyses.

Data analysis

RAPD and ISSR repeatable bands were scored as present (1) or absent (0), and each characteristic state was treated independently. For each primer, the number of different bands and the frequency of polymorphic bands were calculated. Genetic similarity and cluster analysis were performed by calculating Jaccard's similarity index and the resulting genetic distance matrix (Treecon software, Van de Peer and de Wachter 1994) and by generating dendrograms (UPGMA) using Statistica 7.0 software (Statsoft, Groningen, The Netherlands). For quantitative morphological characteristics, an ANOVA analysis was performed, homogeneous groups (Newman and Keuls) were determined and intra-landraces CV were calculated by using Statistica 7.0 software. Distance matrices for morphological characteristics based on Gower's distance between pairs of landraces were calculated by using SAS 9.1 (SAS Institute Inc., Cary, USA), and dendrograms were constructed from these matrices with Statistica 7.0 software using the UPGMA clustering algorithm. Analysis of molecular variance (AMOVA) was performed using Arlequin ver. 2 (Schneider et al. 2000). AMOVA was done first to analyse the variability intra and inter-landraces and second among and within geographical regions.

Correlations between molecular, morphological and geographical Euclidean distance matrices, and correlation between each similarity matrix (i.e., RAPD and ISSR), were performed by Mantel test using Passage software 1.1. (Mantel 1967; Rosenberg 2001).

\section{Results}

Morphological characterization

Morphological comparison was performed within and between the landraces (Table 1) collected throughout 
Algeria (Fig. 1). Two landraces, ND3 from Djanet and NAT9 from Adrar, both in the Sahara, did not flower under our trial conditions; therefore, their morphological characterization could not be completed.

No intra-landrace variation was observed in the qualitative characteristics (data not shown). Each quantitative characteristic was compared among landraces by using ANOVA. The results summarized in Table 4, show that all studied characteristics are significantly different $(P<0.001)$ among landraces. The CV indicated clearly that landrace NAG2 was significantly more variable for all characters than the other landraces. Based on Newman and Keuls comparison, the following groups can be identified. Landraces NE5, NE8, and NE4 have the earliest flowering date, whereas landraces ND4 and NAG2 have the latest.

- Landraces NKB7 and ND6, which came from Kabylia and Djanet, respectively, have the longest pods.

- The two latest landraces (ND4 and NAG2) and landrace NG7, have the highest number of ovules per pod; and

- landrace ND6 has the longest seeds $(1.04 \mathrm{~cm}$ on average).

The qualitative and quantitative data were compared among landraces by using a distance matrix based on Gower's distance to construct a dendrogram (Fig. 2). The dendrogram can be divided into six clusters:

- cluster I, which comprised landraces NE5 and NKT3 characterized by large kidney-shaped seeds ( 0.94 and $0.90 \mathrm{~cm}$, respectively) that both originate from the North of Algeria;

- cluster II, which comprised landraces NE4 and NAG5 (characterized by cream-coloured, globose seeds with black eyes) that both originate from the North of Algeria; however, although these two landraces share similar seed colours and shapes, they differed significantly for quantitative traits (Table 4);

- cluster III, which comprised landraces NE8 and NKT4 characterized by the same qualitative characteristics (seed and eye colour, seed texture, flower colour and absence of purple pigmentation on pod); quantitative characters were not significantly different between these two landraces $(P>0.05)$ (Table 4$)$;

- cluster IV, which comprised landraces NE10, NAT2, NAG6, NAG2, NB12, NB18, NG7 and ND4 characterized by the same seed colour (brown);

- cluster V, which comprised landraces NKT5 and NAG4 (characterized by black seed colour) that originate from very different regions (Kabylia for NKT5, and the Sahara for NAG4); however, although the two landraces have similar seed colours, they differ significantly for quantitative traits (Table 4); and

- cluster VI, which comprise landraces NKB7 and ND6 characterized by the largest pods.

\section{Molecular characterization}

When RAPD markers were applied to the 20 landraces, 77 bands were amplified from 11 primers with an average frequency of seven bands per primer. The size of the individual bands ranged from 311 to 2,604 bp. The mean polymorphism for all bands taken together was $58.44 \%$ (45/77) (Table 3).

When ISSR markers were used on the same landraces, a set of 12 primers revealed 104 bands ranging from 300 to $2,300 \mathrm{bp}$, with each primer having an average of 8.66 bands. Of these, $65(62.5 \%)$ of the bands were polymorphic (Table 3). Regarding to the repeated sequence in ISSR primers the percentage of polymorphism was 74.7, 61.11, 57.69 and $25 \%$ for GA, AG, AC and CA, respectively.

For both ISSR and RAPD markers, no differences were observed between individuals of a same landrace; therefore, the analyses were performed at the landrace level by using distance matrices. AMOVA analysis indicated that the variation within landraces was $0 \%$ both for RAPD and ISSR, the variation between regions was 68.61 and $71.50 \%$ for RAPD and ISSR, respectively and variation among landraces within regions was 31.39 and $28.50 \%$ for RAPD and ISSR, respectively.

Each distance matrix was built based on Jaccard's distance. A dendrogram was generated for each technique separately, along with one for both techniques (Fig. 3a-c). Genetic distances ranged from 0.03 to 0.34 for RAPD, from 0.01 to 0.37 for ISSR, and from 0.02 to 0.35 for the combined RAPD-ISSR 


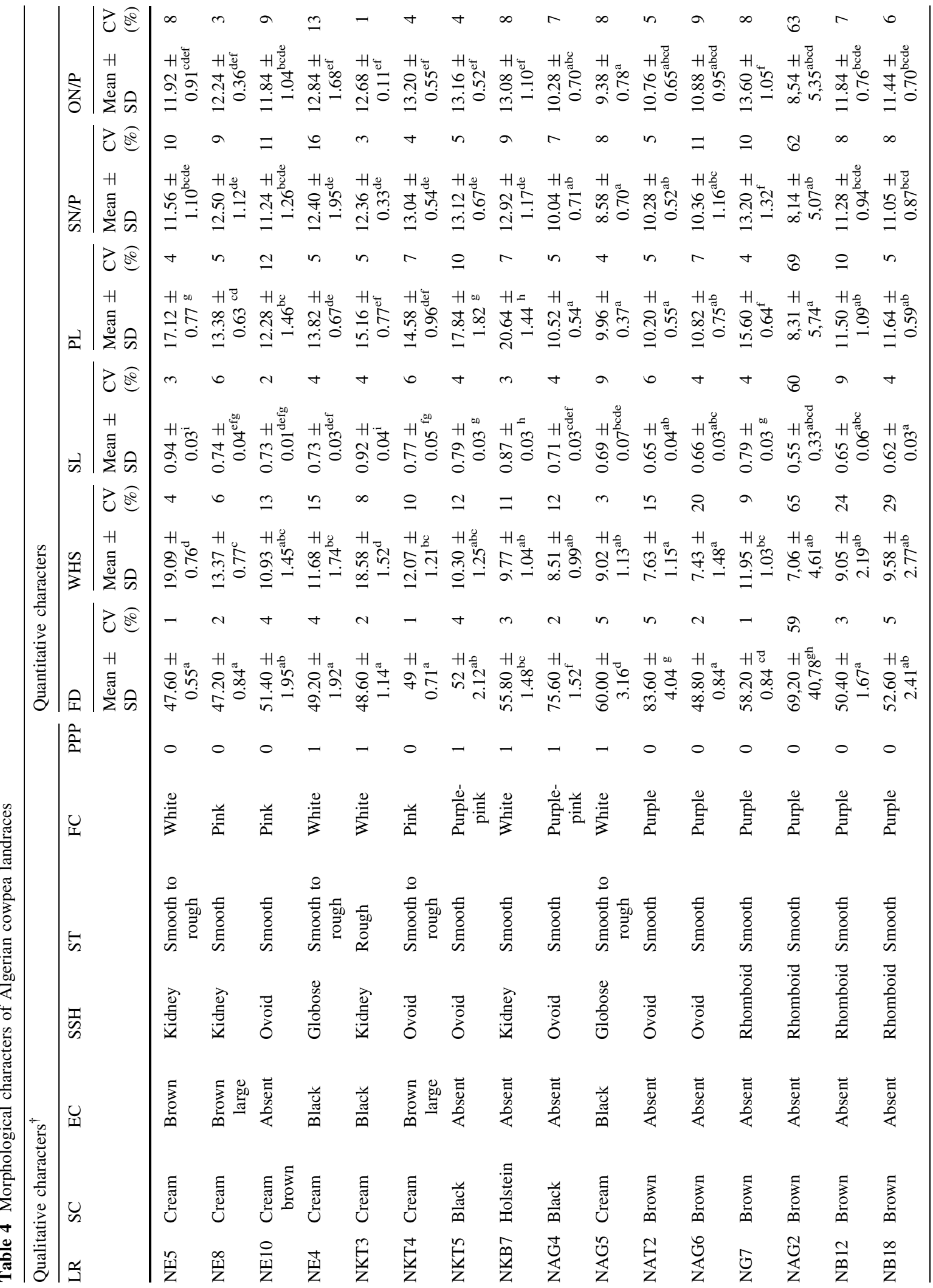




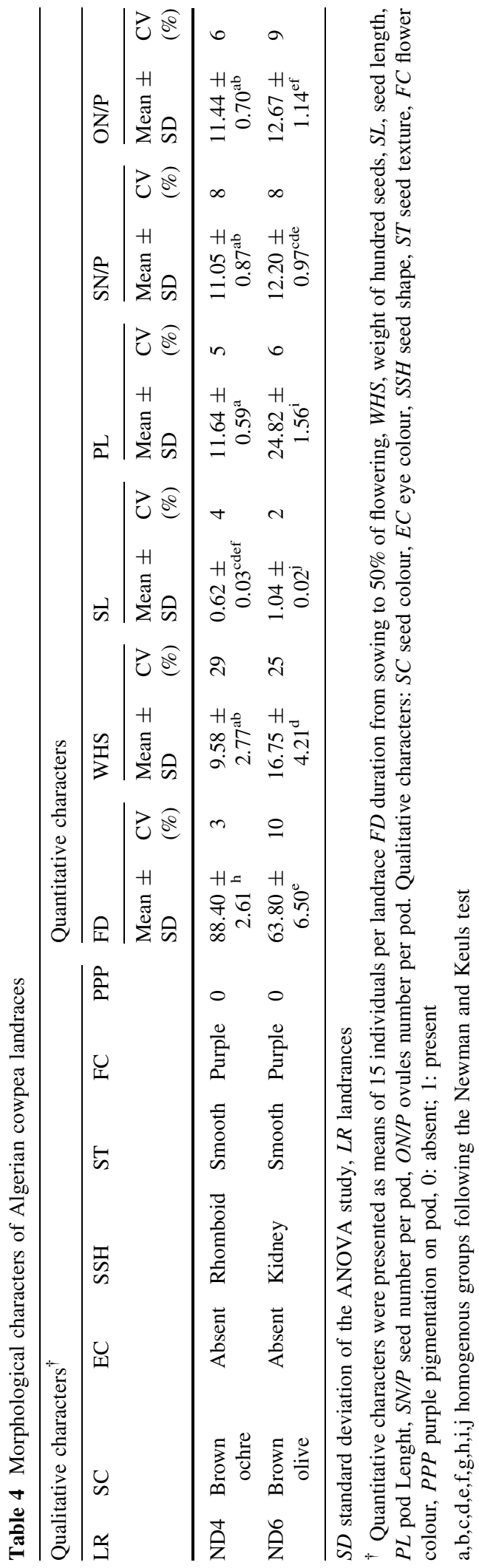

dataset. Although the dendrograms for the RAPD and ISSR techniques were slightly different from each other, the landraces were generally distributed in a similar fashion.

From the RAPD dendrogram (Fig. 3a), we observed six clusters:

- cluster I with landraces from the North of Algeria regions of El Kala (NE5, NE8, NE10, NE4) and Tiziouzou (NKT3, NKT4, NKT5);

- cluster II with landraces from the central regions of Adrar (NAG4, NAG5, NAG6, NAG2), Bechar (NB12, NB18) and Timimoun (NAT2);

- cluster III with landraces from Djanet (ND3 and ND4);

- cluster IV included a single landrace from Bejaia (NKB7);

- cluster $\mathrm{V}$ included a single landrace from El Golea (NG7); and

- cluster VI included a single landrace, ND6, which seems to be slightly different from the other ones and which constitutes a separate cluster, consistent with the morphological data, since ND6 shows a different seed colour (brown-olive) and the longest pods.

For ISSR as for RAPD (Fig. 3b), landraces NKB7, NG7 and ND6 were classified separately indicating that these landraces were genetically separated from the others. The remaining landraces can be divided into five groups:

- cluster I (landraces NE5, NE8, NE10, and NE4) including those from El Kala (North-east);

- cluster II (landraces NKT3, NKT4 and NKT5) including those from Tiziouzou;

- cluster III (landraces NAG4, NAG5, NAT2 and NAG6) including those from Adrar except for landrace NAT9 which is part of Cluster V;

- cluster IV (landraces NAG2, NB12, NB18 and ND3) including those from the neighboring regions of Bechar (NB12, NB18) and Timimoun (NAG2), in association with landrace ND3 which comes from Djanet; and

- cluster V (landraces NAT9, ND4) including one landrace from Adrar (NAT9) and one from Djanet (ND4).

When both the ISSR and RAPD datasets are considered together, 5 clusters could be visualized (Fig. 3c). 
Fig. 2 Dendrogram based on morphological data and Gower's distance

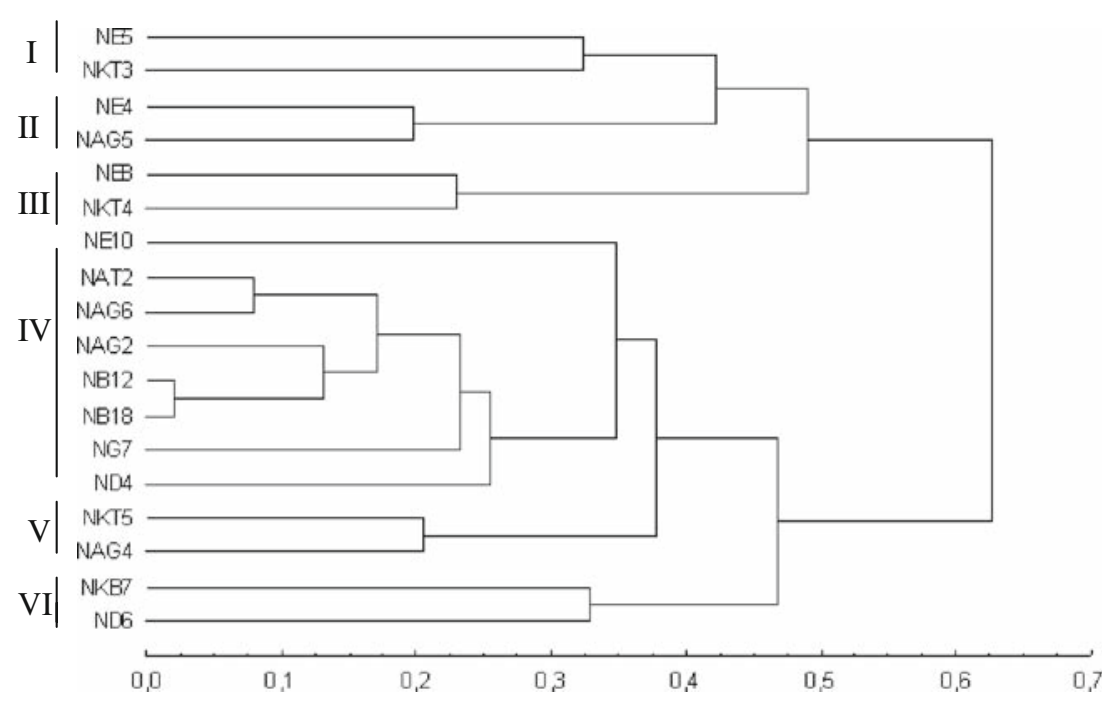

- cluster I with landraces from El Kala (NE5, NE8, NE10 and NE4);

- cluster II with landraces from Tiziouzou (NKT3, NKT4 and NKT5);

- cluster III with landraces from Adrar (NAG4, NAG5, NAT2 and NAG6);

- cluster IV with landraces from the regions of Bechar (NB12, NB18) and Timimoun (NAG2); and

- cluster V with landraces from Djanet (ND3 and ND4).

Once again, landraces NKB7 from Bejaia, NG7 from El Golea and ND6 from Djanet were classified separately.

Congruence of morphological, molecular and geographical data

Firstly, the Mantel test revealed a significant correlation between the qualitative morphological data and the geographical data $(R=0.28 ; P<0.01)$, which indicates that morphological variation corresponds to differences in geographical distribution.

Secondly, there were significant correlations between geographical and genetic data $(R=0.33$; $P<0.01$, for RAPD $), \quad(R=0.37 ; P<0.01$, for ISSR) and $(R=0.33 ; P<0.01$, for RAPD and ISSR combined).

Thirdly, patterns of variation in qualitative morphological data were compared to those of the genetic data. There was not a significant correlation to the genetic data when RAPD markers were used ( $R=0.14 ; P=0.14)$. However, there was a slight and significant correlation when ISSR markers were used $(R=0.27 ; P<0.05)$ and when both RAPD and ISSR markers were evaluated jointly $(R=0.22$; $P<0.05)$. Therefore, ISSR markers more closely reflect the differences in morphological traits encountered between landraces.

Finally, we also used the Mantel test to compare all pairs of genetic matrices. All correlations were very significant $(P<0.01)$. The correlation values were $(R=0.83)$ between ISSR and RAPD. Therefore, the genetic distances between the landraces are similar, independently of the chosen markers.

\section{Discussion}

Cowpea (V. unguiculata) is an important resource for local agriculture in Algeria, and has been cultivated for centuries in many regions (Chevalier 1932). Our study compared 20 landraces originating from these various regions both at the morphological and genetic levels. At the morphological level, qualitative and quantitative traits in 18 landraces were considered. If we considered the intra-landraces variations, our results showed first that for qualitative characters no variation was observed and second that for quantitative traits, the variation was generally low except for 
Fig. 3 Dendrograms showing relationships among Algerian cowpea accessions, using RAPD (a), ISSR (b), and both RAPD and ISSR markers (c), based on Jaccard's distance
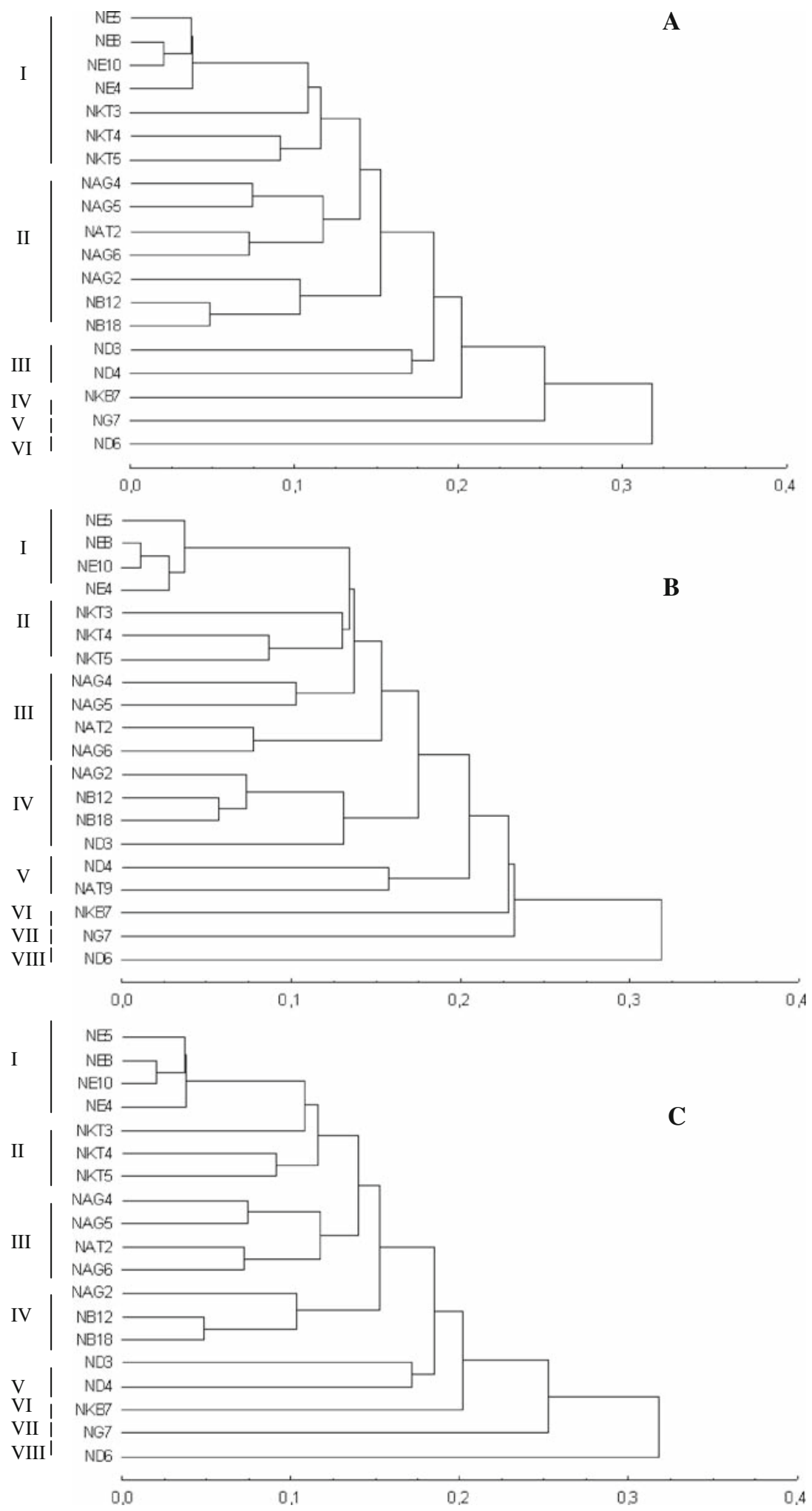
NAG2 that showed significantly higher $\mathrm{CV}$ values for all characters. The abnormal behaviour of this particular landrace could be due to its susceptibility to anthracnose into this landrace during the assay. We hypothesized that NAG2 could be more susceptible to anthracnose than the other landraces. Another explanation is that this landrace originated from Timimoun (Sahara) adapted badly or in a variable way to the northern environmental conditions.

The intra-landrace homogeneity is quite logical for a self-pollinated plant. Landraces of self-pollinated crops such as cowpea often possess low withinaccession variability (Nkongolo 2003). The traditional agricultural practice of cowpea cultivation in Algeria (consisting of the cultivation of the seeds obtained from the same field in subsequent generations without the importation of foreign seeds) probably contributes to genetic uniqueness by strengthening specific, local adaptations (Ehlers and Hall 1997; Li et al. 2001; Badiane et al. 2004).

The degree of homogeneity that we observed led us to compare landraces instead of individual plants. These comparisons were performed in different ways. For morphological characters, the grouping analysis indicated that the variability among landraces was greater for quantitative traits than for qualitative traits.

There are close relationships among some of the landraces in this study, presumably because they have been collected from similar locations with similar climate and soil type and there is seeds exchange between farmers of closed regions. These relationships are reflected in our assignments of landraces to cultivar groups. The genetic distances observed between the Algerian landraces that we evaluated were relatively low, suggesting a common origin. Slight genetic variation was also observed in a previous study (Echikh 2000) of cowpea landraces collected in several Algerian areas of traditional agriculture (the Kabylian Mountains: Tiziouzou in the North and oases in the South: Djanet, Timimoun, El Golea and Adrar), based on isoenzyme polymorphisms. However, in neither study were Algerian landraces compared to landraces from other countries. Nevertheless, higher levels of within-country variation have been reported. For example, greater genetic variation was described in Malawian cowpea landraces where the genetic distance between landraces reached 0.57 (Nkongolo 2003).
Morphological classification and cultivar groups

Differences among Algerian landraces are related both to geographic distance (i.e., environmental variation) and likely to differences in end use, reflected in their cultivar-group assignment. We can classify these landraces into three of the five existing cultivar groups (Pasquet 1998). Saharian landraces with black or brown seeds (NAG4, NAT2, NAG6, NAG2, NB12, NB18 and ND4), together with a brown-seeded landrace from El Kala (NE10) and a black-seeded landrace from Kabylia (NKT5), belong to cultivar group Biflora, which is characterized by short pods with few locules, small, coloured seeds that can be either smooth or cylindrical, and flowers that are most often coloured (Pasquet 2000; Padulosi 1993). This cultivar group is present in the whole Sudanese-Sahelian area and in oases of the Sahara (Chevalier 1944). Our results agree with a study that classified the Saharian forms into group Biflora (Echikh 2000). Echikh (2000) indicated that the Saharian forms were characterized by small, black, cream brown or brown and smooth testa seeds.

Notably, in comparison to landraces from South Algeria, Biflora landraces from the North produce longer pods and bigger seeds. Following our investigation performed during prospection (data not shown). Northern landraces NE10 and NKT5 appears to be originated from Sahara and were further adapted to local conditions.

The other Kabylian landraces (NKT3, NKT4), together with some landraces from El Kala (NE5, NE8 and NE4) and some Saharian landraces (NAG5 and NAT9), shared morphological characteristics with Melanophtalmus cultivar group (Pasquet 1998), including rough seeds, flower and seeds partly white and fewer than 17 ovules. Echikh (2000) classified Kabylian landraces under group Melanophtalmus, which includes photo-independent cultivars that can be harvested twice a year. Moreover, we noted that the Saharian forms (NAG5 and NAT9) which share the same qualitative characteristics (seed colour, seed texture, seed shape, flower colour, and pod pigmentation) with group Melanophtalmus have later flowering dates and low production under the soil and climatic conditions of North Algeria, suggesting that these Saharian landraces (NAG5 and NAT9) were narrowly adapted to local agroclimatic conditions. 
Echikh (2000) showed that the Saharian forms belonging to cultigroup Biflora seems to be more polymorphic than the Kabylian forms belonging to cultigroup Melanophthalmus. The Saharian forms have been introduced from North-East Africa, that could be a possible centre of domestication of cultivated forms of V. unguiculata (Echikh 2000; Pasquet 2000). Variation in the initial genetic stocks may have been preserved because of the extreme isolation of Saharan oases (Echikh 2000).

Morphological characteristics (Table 2) of landraces ND6 from Djanet, NKB7 from Bejaia, and NG7 from $\mathrm{El}$ Golea indicated that these landraces belong to group Unguiculata, which includes cultivars with smooth, rhomboid seeds 6-12 $\mathrm{mm}$ long and pods with lengths that range from 12 to $30 \mathrm{~cm}$ and many locules (Pasquet 1994; Westphal 1974).

Genetic classification

Surprisingly, all individuals of the same landrace were genetically identical according to both RAPD and ISSR. The variability among landraces was therefore very low. It is coherent with observations for morphological characters. Nkongolo (2003) reported that accessions of self-pollinated crops such as cowpea often possess low within-accession variability.

Previous studies using alloenzymes, RAPD, and microsatellites typically indicate little variation within and between cowpea accessions (Doebley 1989; Pasquet 2000; Li et al. 2001; Tosti and Negri 2002). Cowpea has most likely been domesticated only once (Pasquet 1999), unlike common bean (Phaseolus vulgaris L.) which resulted from at least two domestication events (Singh et al. 1991). Relatively low levels of genetic diversity both within and between landraces of cultivated cowpea may be a result of an initial, single bottleneck (Pasquet 2000).

Random amplified polymorphic DNA, a method widely used to study genetic polymorphism in cowpea (Ba et al. 2004; Nkongolo 2003; Badiane et al. 2004; Fall et al. 2003), revealed high levels of polymorphism (from 73 to 93\%) among landraces of Bambara groundnut (Vigna subterranea (L.) Verdc.) (Massawe et al. 2002). Remarkably, two cowpea studies with RAPD markers also revealed relatively high levels of diversity, one in diverse domesticated and wild cowpea accessions from Africa and South
East Asia (Ba et al. 2004), and the other in Malawian cowpea landraces (Nkongolo 2003).

In contrast, other studies with RAPD markers described lowers levels of polymorphism, e.g., $12 \%$ (Menendez et al. 1997) and $18.5 \%$ (Tosti and Negri 2002). Our study showing genetic polymorphism (58\% of polymorphic bands) among 20 cowpea landraces was based on the use of pre-screened, highly-informative primers ( $\mathrm{Ba}$ et al. 2004). The individuals belonging to the same landrace gave the same genetic profiles which underlined their genetic homogeneity.

Thus, all our genetic comparisons were performed at the landrace level. RAPD markers showed that pair-wise genetic distances ranged from 0.033 (between landraces NE3 and NE10) to 0.34 (landraces NE5 and ND6). These results are comparable to those obtained for black gram (Vigna radiata (L.) Wilcz.) on 32 Indian cultivars, where genetic distances ranged from 0.06 to 0.30 (Lakhanpaul et al. 2000).

Some geographical homogeneity exists within clusters (Fig. 3a) since cluster I comprises landraces from northern Algeria, cluster II comprises most of the landraces from Central Algeria, and cluster III comprises landraces from South-eastern Algeria. However, three landraces appeared to be different: NKT7, from Bejaia in northern Algeria, NG7, from El Golea in Central Algeria, and landrace ND6, from Djanet in South-eastern Algeria. Therefore, geographical origin alone cannot explain genetic variations within cowpea landraces in Algeria. AMOVA analysis showed that the variability among geographical regions was higher than the variability within regions. Therefore, it suggests that the landraces present in the same region were genetically more related and probably belong to the same cultigroup.

Inter-simple sequence repeat markers have been successfully used to analyze repeated motifs in mung bean (Vigna mungo (L.) Hepper) (Singh et al. 2000), genetic relationships among Vigna species (Ajibade et al. 2000), and varietal identification in black gram (Vigna radiata (L.) Wilcz.) (Ranade et al. 2000). The discriminatory potential for ISSR markers depends on the variety and frequency of microsatellites, which change with species and the SSR motifs that are targeted. The sequence of repeats and anchored nucleotides were selected in a way to allowed analysis of multiple loci in a single, multiplexed 
reaction (Depeiges et al. 1995). The reproducibility of the fragments generated by ISSR primers exceeds that of primers of arbitrary sequences typically used for RAPD analysis as described previously (Ajibade et al. 2000).

When ISSR markers were analyzed, tested landraces were once again found to be homogeneous: no intra-landrace differences were observed. The clusters produced from ISSR markers (Fig. 3b) were similar to those found by using RAPD. Once again, landraces NKB7, NG7, and ND6 clearly differ from the larger group and also from each other.

In our study, the level of observed polymorphism was high (62.5\% of polymorphic bands). The number of total polymorphic and discriminant fragments was found to be higher when using ISSR than when using RAPD. Similar results were obtained for several other plant species in previous studies (peanut, common bean, chestnut, black gram) (Raina et al. 2001; Marotti et al. 2007; Goulao et al. 2001, Souframanien and Gopalakrishna 2004). This is not unexpected since the ISSR technique amplifies microsatellite regions that are potentially polymorphic (Marotti et al. 2007). In fact, ISSR has a high capacity to reveal polymorphism and offers great potential to determine intra and inter-genomic diversity in comparison to other arbitrary primers based technique like RAPD (Zietkiewicz et al. 1994). However, in rice bean (Vigna umbellata (Thunb.) Ohwi et $\mathrm{H}$. Ohashi) more polymorphic loci were detected with RAPD (70.30\%) than with ISSR fingerprinting (61.79\%) (Muthusamy et al. 2008).

Our analysis showed that primers with the repeated sequences $\mathrm{AC}, \mathrm{CA}, \mathrm{AG}$ and GA produced a more important number of polymorphisms, confirming the results of a previous study (Ajibade et al. 2000). The latter indicated that two repeated types (GA and CA) revealed approximately equal levels of polymorphism. The eight primers containing GA repeats taken together and the four primers containing CA repeats generated 59 and $58 \%$ of the polymorphic bands, respectively. It which means that they are appropriate for phylogenetic analysis in Vigna.

When taken together, RAPD and ISSR analyses on the 19 common landraces confirmed the previous conclusions but with greater detail. The cluster analysis (Fig. 3c) indicated that the combination of RAPD and ISSR markers gave better results than utilization of a single marker class. In addition, excepting for the three particular landraces probably belonging to the same cultigroup unguiculata, genetic diversity within landraces is coherent with geographical distribution with the presence of the landraces of both cultigroups Biflora and Melanophtalmus among each region. Significant correlations in the Mantel test underline this conclusion.

A high degree of congruence was obtained among compared landraces when using RAPD and ISSR data. This can be explained by the fact that these are both PCR-based methods using non specific primers and giving PCR fragments of the same size ranges.

\section{Conclusion}

In conclusion, this study reveals for the first time how Algerian cowpea landraces can be classified in relation to the major described cultivar groups and their geographic origins through both molecular and morphological characterization. Genetic intra-accession variability was not found, and inter-accession variability is low within clusters and between major clusters, except for three clearly different landraces. Three different cultigroups were located in Algeria: Biflora that was dominant in the Sahara, Melanophtalmus in the North and Unguiculata including one landrace in Kabylia and two in Sahara. Finally, our results demonstrate that RAPD and ISSR techniques can both be used for quantifying genetic distances among cowpea landraces. Breeders can maximize the use of genetic resources by keeping in mind these genetic differences among Algerian landraces.

Conservation of Algerian traditional landraces is urgently needed before they are lost. Future investigations should consider developing Algerian landraces for their drought-resistance potential and other unique traits, especially in the case of Saharian ones, which are especially well adapted to arid environments.

Acknowledgments The authors are grateful to the Algerian Ministry of Higher Education and Scientific Research (Ministère de l'Enseignement Supérieur et de la Recherche Scientifique) for its financial support. We thank the "Laboratory of Molecular Biology of Walloon Agricultural Research Centre of Gembloux" for valuable technical assistance and Dr Bernard China for his critical reading of the manuscript. N. Ghalmi thanks the "Institut Technique des Cultures Maraîchères" of Staouéli for its contribution to the morphological assay. 


\section{References}

Ajibade SR, Weeden NF, Chite SM (2000) Inter simple sequence repeat analysis of genetic relationships in the genus Vigna. Euphytica 111:47-55

Anoun N, Echikh N (1990) Étude biosystématique d'une légumineuse saharienne: le Tadelaght. Mémoire DES. Univ. Sci. Technol. Houari Boumedienne. Bab Ezzouar, Algeria, $101 \mathrm{pp}$

Ba FS, Pasquet RS, Gepts P (2004) Genetic diversity in cowpea [Vigna unguiculata (L.) Walp.] as revealed by RAPD markers. Genet Resour Crop Evol 51:539-550

Badiane FA, Diouf D, Sané D, Diouf O, Goudiaby V, Diallo N (2004) Screening cowpea (Vigna unguiculata (L.) Walp.) varieties by inducing water deficit and RAPD analyses. Afr J Biotechnol 3:174-178

Blair MW, Panaud O, McCouch SR (1999) Inter-simple sequence repeat (ISSR) amplification for analysis of microsatellite motif frequency and fingerprinting in rice (Oryza sativa L.). Theor Appl Genet 98:780-792

Charters YM, Wilkinson MJ (2000) The use of self-pollinated progenies as 'in-groups' for the genetic characterization of cocoa germplasm. Theor Appl Genet 100:160-166

Chevalier A (1932) Productions végétales du Sahara. Rev Bot Appl Agric Trop 12:133-134

Chevalier A (1944) Le dolique de Chine en Afrique. Son histoire, ses affinités, les formes sauvages et cultivées. Son rôle dans l'alimentation indigène et en agriculture tropicale et sub-tropicale. Rev Bot Appl Agric Trop 24:128152

Depeiges A, Goubely C, Lenoir A, Cocherel S, Picard G, Raynal M, Grellet F, Delseny M (1995) Identification of the most represented repeat motifs in Arabidopsis thaliana microsatellite loci. Theor Appl Genet 91:160-168

Dikshit HK, Jhang T, Singh NK, Koundal KR, Bansal KC, Chandra N, Tickoo JL, Sharma TR (2007) Genetic differentiation of Vigna species by RAPD, URP and SSR markers. Biol Plant 51:451-457

Diouf D, Hilu KW (2005) Microsatellites and RAPD markers to study genetic relationships among cowpea breeding lines and local varieties in Senegal. Genet Resour Crop Evol 52:1057-1067

Doebley J (1989) Isozymic evidence and the evolution of crop plants. In: Soltis DE, Soltis PS (eds) Isoenzymes in plant biology. Dioscorides Press, Portland, pp 165-191

Echikh N (2000) Organisation du pool génique de formes sauvages et cultivées d'une légumineuse alimentaire, Vigna unguiculata (L.) Walp. Ph.D. thesis, Faculté Universitaire des Sciences Agronomiques de Gembloux, Gembloux, Belgium, 307 pp

Ehlers JD, Hall AE (1997) Cowpea (Vigna unguiculata (L.) Walp.). Field Crops Res 53:187-204

Eloward HOA, Hall AE (1987) Influence of early and late nitrogen fertilization on yield and nitrogen fixation of cowpea under well-watered and dry field conditions. Field Crops Res 15:229-244

Fall L, Diouf D, Fall-Ndiaye MA, Badiane FA, Gueye M (2003) Genetic diversity in cowpea [Vigna unguiculata (L.) Walp.] varieties determined by ARA and RAPD techniques. Afr J Biotechnol 2:48-50
Fang DQ, Roose ML (1997) Identification of closely related citrus cultivars with inter-simple sequence repeat markers. Theor Appl Genet 95:408-417

Gillaspie AG, Hopkins MS, Dean RE (2005) Determining genetic diversity between lines of Vigna unguiculata subspecies by AFLP and SSR markers. Genet Resour Crop Evol 52:245-247

Goulao L, Valdiviesso T, Santana C, Oliveira CM (2001) Comparison between phenetic characterisation using RAPD and ISSR markers and phenotypic data of cultivated chestnut (Castanea sativa Mill.). Genet Resour Crop Evol 48:329-338

Hall AE, Patel PN (1985) Breeding of resistance to drought and heat. In: Singh SR, Rachie KO (eds) Cowpea research. Production and utilization. Wiley, New York, pp 137-151

International Board for Plant Genetic Resources (IBPGR) (1983) Cowpea descriptors. IBPGR, Rome (34 pp)

Jones CJ, Edwards KJ, Castaglione S, Winfield MO, Sala F, Van De Wiel C (1997) Reproducibility testing of RAPD, AFLP and SSR markers in plants by a network of European laboratories. Mol Breeding 3:381-390

Kwapata MB, Hall AE (1985) Effects of moisture regime and phosphorus on mycorrhizal infection, nutrient uptake and growth of cowpeas (Vigna unguiculata (L.) Walp.). Field Crops Res 12:241-250

Lakhanpaul S, Chadha S, Bhat KV (2000) Random amplified polymorphic DNA (RAPD) analysis in Indian mungbean [Vigna radiata (L.) Wilczek] cultivars. Genetica 109:227234

Leakey CLA (1988) Genotypic and phenotypic markers in common bean. In: Gepts P (ed) Genetic resources of Phaseolus bean. Kluwer, Dordrecht, pp 245-327

Li CD, Fatokun CA, Ubi B, Singh BB, Scoles GJ (2001) Determining genetic similarities and relationships among cowpea breeding lines and cultivars by microsatellite markers. Crop Sci 41:189-197

Mantel N (1967) The detection of disease clustering and generalized regression approach. Cancer Res 27:209-220

Marotti I, Bonetti A, Minelli M, Catizone P, Dinelli G (2007) Characterization of some Italian common bean (Phaseolus vulgaris L.) landraces by RAPD, semi-random and ISSR molecular markers. Genet Resour Crop Evol 54:175-188

Massawe FJ, Roberts JA, Azam-Ali SN, Daved MR (2002) Genetic diversity in bambara groundnut (Vigna subterranea (L.) Verdc.) landraces assessed by random amplified polymorphic DNA (RAPD) markers. Genet Resour Crop Evol 50:737-741

Menendez CM, Hall AE, Gepts P (1997) A genetic linkage map of cowpea (Vigna unguiculata) developed from a cross between two inbred, domesticated lines. Theor Appl Genet 95:1210-1217

Muthusamy S, Kanagarajan S, Ponnusamy S (2008) Efficiency of RAPD and ISSR markers system in accessing genetic variation of rice bean (Vigna umbellata) landraces. Electr J Biotech 11(3): 10 pp. doi: 10.2225/vol11-issue3fulltext-8

Ng NQ, Marechal R (1985) Cowpea taxonomy, origin and germplasm. In: Singh SR, Rachie KO (eds) Cowpea research, production and utilization. Wiley, New York, pp 11-21 
Nkongolo KK (2003) Genetic characterization of Malawian cowpea (Vigna unguiculata (L.) Walp.) landraces: diversity and gene flow among accessions. Euphytica 129:219-228

Ouédraogo JT, Gowda BS, Jean M, Close TJ, Ehlers JD, Hall AE, Gillaspie AG, Roberts PA, Ismail AM, Bruening G, Gepts P, Timko MP, Belzile FJ (2002) An improved genetic linkage map for cowpea (Vigna unguiculata L.) combining AFLP, RFLP, RAPD, biochemical markers, and biological resistance traits. Genome 45:175-188

Padulosi S (1993) Genetic diversity, taxonomy and ecogeographic survey of the wild relatives of cowpea (Vigna unguiculata (L.) Walp.). Ph.D. dissertation, Universite' catholique Louvain-la- Neuve, Belgium, 477 p

Pasquet R (1994) Organisation génétique et évolutive des formes spontanées et cultivées du niébé, Vigna unguiculata (L.) Walp. biosystématique et processus de domestication. Ph.D. thesis, Paris Grignon, I.N.A. ParisGrignon-ORSTOM, France, $284 \mathrm{p}$

Pasquet RS (1998) Morphological study of cultivated cowpea Vigna unguiculata (L.) Walp. Importance of ovule number and definition of cv. gr Melanophthalmus. Agronomie 18:61-70

Pasquet RS (1999) Genetic relationships among subspecies of Vigna unguiculata (L.) Walp. based on allozyme variation. Theor Appl Genet 98:1104-1119

Pasquet RS (2000) Allozyme diversity of cultivated cowpea Vigna unguiculata (L.) Walp. Theor Appl Genet 101:211219

Qian W, Ge S, Hong DY (2001) Genetic variation within and among populations of a wild rice Oryza granulata from China detected by RAPD and ISSR markers. Theor Appl Genet 102:440-449

Raina SN, Rani V, Kojima T, Ogihara Y, Singh KP, Devarumath RM (2001) RAPD and ISSR fingerprints as useful genetic markers for analysis of genetic diversity, varietal identification, and phylogenetic relationships in peanut (Arachis hypogaea) cultivars and wild species. Genome 44:763-772

Ranade R, Vaidya UJ, Kotwal SA, Bhagwat A, Gopalakrishna $\mathrm{T}$ (2000) Hybrid seed genotyping and plant varietal identification using DNA markers. In: DAE-BRNS symposium on the use of nuclear and molecular techniques in crop improvement, 6-8 December 2000, Mumbai, India, pp 338-345

Rosenberg MS (2001) Passage. pattern analysis, spatial statistics, and geographic exegesis. Version 1.1. Department of Biology, Arizona State University, Tempe

Sarutayophat T, Nualsri C, Santipracha Q, Saereeprasert V (2007) Characterization and genetic relatedness among 37 yardlong bean and cowpea accessions based on morphological characters and RAPD analysis. Songklanakarin J Sci Technol 29:591-600

Schneider S, Roessli D, Excoffier L (2000) Arlequin ver 2.000; a software for population genetics data analysis. Genetics and biometry laboratory, Dept of Anthropology and ecology, University of Geneva, Suisse

Singh SP, Nodari R, Gepts P (1991) Genetic diversity in cultivated common bean. 1. Allozymes. Crop Sci 31:19-23

Singh BB, Chambliss OL, Sharma B (1997) Recent advances in cowpea breeding. In: Singh BB, Mohanraj DR, Dashiell KE, Jackai LEN (eds) Advances in cowpea research. IITA-JIRCAS, Ibadan, pp 30-49

Singh S, Reddy KS, Jawali N (2000) PCR analysis of mungbean genotypes using anchored simple sequence repeat primers. In: DAE-BRNS symposium on the use of nuclear and molecular techniques in crop Improvement. BARC, Mumbai, India, pp 359-369

Souframanien J, Gopalakrishna T (2004) A comparative analysis of genetic diversity in blackgram genotypes using RAPD and ISSR markers. Theor Appl Genet 109:16871693

Tosti N, Negri V (2002) Efficiency of three PCR-based markers in assessing genetic variation among cowpea (Vigna unguiculata subsp. unguiculata) landraces. Genome 45:268-275

Trabut A (1935) Répertoire des noms indigènes des plantes spontanées cultivées et utilisées dans le nord de l'Afrique. Algiers, Algeria, 355 pp

Van de Peer Y, de Wachter Y (1994) TREECON for windows: a software package for the construction and drawing of evolutionary trees for the microsoft environment. Comput Appl Biosci 10:569-570

Welsh J, Mc Clelland M (1990) Fingerprinting genomes using PCR with arbitrary primers. Nucleic Acids Res 18:72137218

Westphal E (1974) Pulses in Ethiopia: their taxonomy and agriculture significance. Agricultural research report 815 . Center for Agricultural Publishing and Documentation, Wageningen

Xue-Jun G, Yan Y, Yong-Ming Y, Hong-Wen H, Cheng Y (2005) Genetic diversity and geographic differentiation in endangered Ammopiptanthus (Leguminosae) populations in desert regions of northwest china as revealed by ISSR analysis. Ann Bot 95:843-851

Zietkiewicz E, Rafalski A, Labuda D (1994) Genome fingerprinting by simple sequence repeat (SSR)-anchored polymerase chain reaction amplification. Genomics 20:176-183 